\title{
An assessment of Antimicrobial Activity of Three Endodontic Sealers on Enterococcus faecalis, Candida albicans and Staphylococcus aureus by a Direct Contact Test: An In Vitro Study
}

Trishnika Chakraborty ( $\nabla$ trishnikasrija11@gmail.com )

Chaudhary Charan Singh University https://orcid.org/0000-0002-1389-2437

Sonali Taneja

Chaudhary Charan Singh University

Research article

Keywords: Candida albicans, direct contact test, Enterococcus faecalis, endodontic sealers,

Staphylococcus aureus

Posted Date: August 26th, 2020

DOI: https://doi.org/10.21203/rs.2.16983/v2

License: (c) (1) This work is licensed under a Creative Commons Attribution 4.0 International License.

Read Full License 


\section{Abstract}

For successful endodontic treatment, the antimicrobial property of endodontic filling is mandatory. Hence, the aim of this in vitro study was to assess the antibacterial efficacy of three endodontic sealers on Enterococcus faecalis, Candida albicans and Staphylococcus aureus by direct contact test (DCT).

Materials and Methods

The antimicrobial efficacy of three different sealers, AH Plus, MTA Fillapex and Endo Sequence BC, was tested against Enterococcus faecalis ATCC 29212, Candida albicans ATCC 10231 and Staphylococcus aureus ATCC 25923 by DCT. Freshly mixed sealers were placed in flat bottom test tubes incubated at $37^{\circ} \mathrm{C}$. Thereafter, $10 \mu \mathrm{L}$ of suspension was drawn and spread over culture plates to determine the colony count using a digital colony counter. Readings were taken at $1 \mathrm{hr}$ (fresh specimen), and then at $24 \mathrm{hrs}$ (after setting). The results were tabulated, and statistical analysis was performed using one-way ANOVA and Tukey's HSD test.

Results

DCT showed a significant decrease in microbial count in AH Plus, MTA Fillapex and Endoseq BC at both time intervals. Group 3 (Endosequence BC) showed minimum microbial count followed by Group 2 (MTA Fillapex) and maximum microbial count for Group 1 (AH Plus) for both time intervals (1 hour and 24 hours).

Conclusion

Endosequence $\mathrm{BC}$ showed maximum antimicrobial efficacy against all the tested microorganisms for both time intervals, followed by MTA Fillapex and AH Plus.

\section{Introduction}

The exclusion of microorganisms from the root canal is the priority of endodontic treatment. This is implemented by biomechanical preparation, irrigation with irrigants and satisfactory filling of the threedimensional root canal [1]. The failure in the treatment is dominated by facultative and resistant microbial species. The persistent periradicular lesions after root canal treatment are due to the presence of Enterococcus faecalis (E. faecalis) [2]. Enterococci have the ability to grow in environments of low nutrients, which can also survive as mono-infections. According to Sundqvist et al., $38 \%$ of failed root canal systems were commonly associated with E. faecalis. Candida albicans (C. albicans), a dentinophilic microorganism, is associated with failed treatment [3]. Refractory periapical disease is associated with biofilms of Staphylococcus aureus (S. aureus) on tissues. Hence, these organisms were used as our study parameters. The application of sealers with antibacterial properties has further lowered the remaining microorganisms. One of the most common epoxy resin-based sealers is AH Plus (Dentsply 
International Inc., York, PA), which is eugenol-free, biocompatible and radio-opaque. Paste A of AH Plus has bisphenol-A epoxy resins. It also contains zirconium oxide, silica, iron oxide pigments and calcium tungstate. Paste B contains tricyclodecane-diamine, dibenzyldiamine, aminoadamantane, calcium tungstate, silica, zirconium oxide, and silicone oil [4]. Mineral trioxide aggregate (MTA) was used as a sealer after modifications. MTA-Fillapex has good biocompatibility and capacity in the formation of mineralized tissues. MTA Fillapex can also be used as perforation repair material in root canals. It is also used as retrograde filling material and in cases of apexification $[5,6]$. Currently, bioceramic sealers are used as root repair materials and sealers because of their biocompatibility and alkaline pH $(<12)$. It has other advantages, such as being easily introducible in canals, non-shrinkable and non-resorbable. Studies have shown that bioceramic sealers strengthen the root canal following obturation. One of the newer bioceramic endodontic sealers is Endosequence BC Sealer (Brasseler, Savannah, GA, USA), which mainly comprises zirconium oxide and calcium phosphate. It also consists of calcium silicates and calcium hydroxide $[7,8]$. The agar diffusion test (ADT), a semiquantitative technique, is the most frequent method used to study in vitro antimicrobial activities. ADT cannot differentiate between bacteriostatic and bactericidal effects of materials. The outcome is influenced by the diffusibility and solubility of the biomaterials through the agar. Hence, it is not used for water insoluble materials [9]. Therefore, the methodology adopted was the direct contact test (DCT). DCT by Weiss et al measures the effect between the tested microorganism and the material when they are in contact on the basis of microbial viability. It measures the antimicrobial property of the biomaterial irrespective of the solubility and diffusibility of the tested materials. DCT is a quantitative test and reproducible assay that can also be used to study insoluble biomaterials and can be used for standardized settings [10]. Therefore, the aim of this study was to compare the in vitro antimicrobial efficacy of three endodontic sealers against E. faecalis, C. albicans and $\mathrm{S}$. aureus by using a direct contact test. The null hypothesis tested was that there were no differences in the antimicrobial efficacy of Endosequence BC Sealer, MTA- Fillapex and AH Plus against E. faecalis, S. aureus and C. albicans.

\section{Methods}

Grouping of Sample

This study was divided into 3 groups based on the following sealers.

1= AH Plus, 2= MTA Fillapex and 3= Endo Sequence BC

Depending on the microorganisms to be tested, these three groups were further subdivided into 3 groups of 18 each:

Sub Group A: E. faecalis $(n=18)$, Sub Group B: C. albicans $(n=18)$ and Sub Group C: S. aureus $(n=18)$.

Nine samples from each subgroup were analysed at 1 hour, and the remaining nine samples were analysed after 24 hours. For this study, bacterial growth was measured by a microplate spectrophotometer. For DCT, $50 \mathrm{mg}$ of sealer was mixed and settled in nine flat bottom tubes. The tubes 
for each sealer were prepared in triplicate. Then, $50 \mu \mathrm{L}$ of $0.5 \mathrm{ml} \mathrm{McFarland} \mathrm{standard} \mathrm{suspension}(1.5 \mathrm{x}$ $10^{8} \mathrm{CFU} / \mathrm{ml}$ ) of microorganisms was spread over the sealers. McFarland standards were used as a reference to evaluate the number of bacteria within a given range to standardize the microbial testing. It is based on the turbidity of bacterial suspensions. The samples were then incubated at $37^{\circ} \mathrm{C}$ to ensure direct contact between bacteria and test sealers. The suspension of microorganisms and test sealers were in direct contact for 1 hour and 24 hours. The test tubes were incubated at $37^{\circ} \mathrm{C}$, after which the test tubes were inspected for evaporation of the suspension.

Ethics

Ethical clearance was taken from the ethical committee institute.

Statistics

The data were analyzed using SPSS 16.0. The intergroup comparison for normal data was tested by oneway ANOVA and Tukey's HSD test. The intragroup comparison was tested by paired $t$ test (parametric test). The level of significance and confidence interval were $5 \%$ and $95 \%$, respectively.

\section{Result}

The DCT showed a significant difference in microbial count among the groups (ANOVA $\mathrm{p}=0.0001$ ) at 1 hour and 24 hours. In the paired t test, Group 3 (Endosequence $\mathrm{BC}$ ) showed a minimum microbial count of E. faecalis with a mean difference of 8.980, C. albicans with a mean difference of 7.889 and S. aureus with a mean difference of 6.540 for both time intervals, i.e., $1 \mathrm{hr}$ and $24 \mathrm{hrs}$, and this difference was significant [table 2]. Group 2 (MTA Fillapex) showed the second highest microbial count with a mean difference of 6.322 for E. faecalis, 7.222 for C. albicans and 5.444 for S. aureus for both time intervals [table 1]. In this study, Group 3 showed the highest microbial count of E. faecalis, with a mean difference of 5.444 for $\mathrm{E}$. faecalis and 5.114 for S. aureus for both time intervals, i.e., $1 \mathrm{hr}$ and $24 \mathrm{hrs,}$ and this difference was significant [table 3]. 


\begin{tabular}{|c|c|c|c|c|c|c|c|c|}
\hline & & Mean & $\begin{array}{l}\text { Std. } \\
\text { Deviation }\end{array}$ & $\begin{array}{l}\text { Std. Error } \\
\text { Mean }\end{array}$ & $\begin{array}{l}95 \% \mathrm{Cc} \\
\text { the Dif }\end{array}$ & ee Interval of & $\mathrm{t}$ & $\begin{array}{c}P \\
\text { value }\end{array}$ \\
\hline & & & & & Lower & Upper & value & \\
\hline $\begin{array}{l}\text { Pair } \\
1\end{array}$ & $\begin{array}{l}\text { E.faecalis1 hr. - } \\
\text { E.faecalis24hr. }\end{array}$ & 6.322 & 3.279 & 1.093 & 5.854 & 6.813 & 5.050 & .016 \\
\hline $\begin{array}{l}\text { Pair } \\
2\end{array}$ & $\begin{array}{l}\text { C.albicans1hr- } \\
\text { C.albicans24hr }\end{array}$ & 7.222 & 2.949 & .983 & 7.489 & 4.956 & 6.348 & $<.001^{* \star}$ \\
\hline $\begin{array}{l}\text { Pair } \\
3\end{array}$ & $\begin{array}{l}\text { S.aureus } 1 \mathrm{hr}- \\
\text { S.aureus } 24 \mathrm{hr}\end{array}$ & 5.444 & 3.167 & 1.056 & 5.179 & 1.010 & 5.263 & .011 \\
\hline
\end{tabular}

Table 1. Comparison of means of microbial count between two intervals in MTA Fillapex by paired T test

\begin{tabular}{|c|c|c|c|c|c|c|c|c|}
\hline & & Mean & \begin{tabular}{|l|} 
Std. \\
Deviation
\end{tabular} & $\begin{array}{l}\text { Std. Error } \\
\text { Mean }\end{array}$ & $\begin{array}{l}95 \% \text { Co } \\
\text { the Diff }\end{array}$ & Interval of & $\begin{array}{l}t \text { test } \\
\text { value }\end{array}$ & \begin{tabular}{|c|} 
\\
value
\end{tabular} \\
\hline & & & & & Lower & Upper & & \\
\hline $\begin{array}{l}\text { Pair } \\
1\end{array}$ & $\begin{array}{l}\text { E.faecalis } 1 \mathrm{hr} \text { - } \\
\text { E.faecalis24hr. }\end{array}$ & 8.980 & 2.345 & .782 & 7.803 & 4.197 & 7.675 & $<.001^{* *}$ \\
\hline $\begin{array}{l}\text { Pair } \\
2\end{array}$ & $\begin{array}{l}\text { C.albicans1hr- } \\
\text { C.albicans24hr }\end{array}$ & 7.889 & 2.977 & .992 & |11.177 & 6.601 & 8.958 & $<.001$ <* \\
\hline $\begin{array}{l}\text { Pair } \\
3\end{array}$ & $\begin{array}{l}\text { S. aureus } 1 \mathrm{hr} \\
\text { S.aureus } 24 \mathrm{hr}\end{array}$ & 6.540 & 2.345 & .782 & 7.803 & 4.197 & 7.675 & $<.001^{* *}$ \\
\hline
\end{tabular}

Table 2. Comparison of means of microbial count between two intervals in Endosequence BC by paired T test

\begin{tabular}{|c|c|c|c|c|c|c|c|c|}
\hline & & Mean & $\begin{array}{l}\text { Std. } \\
\text { Deviation }\end{array}$ & $\begin{array}{l}\text { Std. Error } \\
\text { Mean }\end{array}$ & $\begin{array}{l}95 \% \mathrm{Cc} \\
\text { the Dif }\end{array}$ & e Interval of & $\begin{array}{l}t \text { test } \\
\text { value }\end{array}$ & $\begin{array}{c}P \\
\text { value }\end{array}$ \\
\hline & & & & & Lower & Upper & & \\
\hline $\begin{array}{l}\text { Pair } \\
1\end{array}$ & $\begin{array}{l}\text { E.faecalis1hr. - } \\
\text { E.faecalis24hr. }\end{array}$ & 5.444 & 5.503 & 1.834 & 3.674 & 5.215 & -5.149 & .001 \\
\hline $\begin{array}{l}\text { Pair } \\
3\end{array}$ & $\begin{array}{l}\text { S.aureus } 1 \mathrm{hr}- \\
\text { S.aureus } 24 \mathrm{hr}\end{array}$ & 5.114 & 5.503 & 1.834 & 3.674 & 5.215 & -5.149 & . 001 \\
\hline
\end{tabular}

Table 3. Comparison of means of microbial count between two intervals in AH Plus by paired T test * - Significant, **- Highly Significant, NS- Not Significant

\section{Discussion}


The predominant cause of endodontic treatment failure is resistance to microorganisms such as $\mathrm{E}$. faecalis, C. albicans and S. aureus [11]. Bioceramic (Endosequence BC) sealers are known for their antimicrobial properties during setting and exhibit no shrinkage. During setting, hydroxyapatite forms, which chemically bonds to dentin and gutta percha [12]. MTA-based sealers (MTA Fillapex, Angelus, Brazil) are known for their properties, such as remarkable biocompatibility, stimulating mineralization and exhibiting higher push-out strengths than zinc oxide eugenol cements [13]. MTA consists of calcium oxide, which has a similar mode of action to calcium hydroxide [14]. Epoxy resin-based sealers (AH Plus) have good antimicrobial, physical and chemical properties [15]. Hence, these sealers diminish the survival of microorganisms during obturation. The results of the present study showed a significant microbial count reduction with Endosequence BC compared with MTA Fillapex and AH Plus for both time intervals (1 hr and $24 \mathrm{hrs)}$ ). It showed maximum antimicrobial efficacy against E. faecalis, followed by C. albicans and least against $\mathrm{S}$. aureus. These outcomes resembled those of other studies in which fresh Endoseq BC, MTA Fillapex and AH plus had antibacterial action against $\mathrm{E}$. faecalis when tested by a time kill assay [16]. The results were also in accordance with studies in which ADT, DCT, and modified DCT were implemented $[17,18,19,20]$. Endosequence BC showed the lowest microbial count against E. faecalis, followed by $\mathrm{C}$. albicans and $\mathrm{S}$. aureus. The literature search does not have studies to support our result in relation to the highest reduction in Enterococcus faecalis followed by Candida albicans and Staphylococcus aureus using a direct contact test. MTA Fillapex showed maximum antimicrobial efficacy against $\mathrm{C}$. albicans followed by E. faecalis and least against $\mathrm{S}$. aureus. AH Plus showed maximum antimicrobial efficacy against E. faecalis followed by S. aureus and showed no antimicrobial effect against C. albicans.

The antimicrobial property of the $\mathrm{BC}$ sealer is attributed to its alkaline $\mathrm{pH}$, which aids in the exclusion of microorganisms such as $\mathrm{E}$. faecalis that cease to survive at high $\mathrm{pH}$, near 11.5 or more. Additionally, active calcium hydroxide diffusion over the period of time can be the reason for the antimicrobial efficacy [21]. In contrast to our study, Hegde and Rathod (2017) stated that AH Plus sealer had better results than Bioceramic sealer against E. faecalis in their study on Enterococcus faecalis. Such discrepancies can be due to the methodology used in the study, which was the agar diffusion test [22].

MTA Fillapex showed the second most statistically significant microbial count reduction for both time intervals, i.e., 1 hour and 24 hours against $C$. albicans, E. faecalis and S. aureus. This result was in accordance with Rahman H et al. (2017), who found that MTA Fillapex and Real Seal SE both showed antifungal activity, whereas only MTA Fillapex was effective against E. faecalis; the rest of the materials did not show any antimicrobial activity [23]. Another study by Stowe et al. (2013) verified the antimicrobial properties of MTA, which inhibited the growth of both E. faecalis and Streptococcus sanguis [24]. MTA Fillapex, which contains calcium silicate that is in contact with the moisture from dentin, begins the hydration of calcium silicates. The calcium silicate hydrogel and calcium hydroxide give a high $\mathrm{pH}$, which could be related to their antimicrobial properties to MTA Fillapex. [25] In contrast to this study, Ustun et al. (2013) showed that MTA-based sealers have the least antibacterial effect at 20 mins, whereas bioceramic sealers and epoxy resin sealers had maximum antibacterial properties [16]. AH Plus, a resin-based sealer, exhibited the least antimicrobial efficacy. Aravind et al. (2006) evaluated the 
antimicrobial properties of five root canal sealers. The results showed that AH Plus has no antimicrobial action against Candida albicans and Enterococci [26]. The result of Andre Mickel et al. (2003) was in accordance with our study, who also verified AH Plus to show minimum efficiency against E. faecalis [27]. The ineffective property of AH Plus is because of the elimination of formaldehyde. The presence of bisphenol A diglycidyl ether in resin-based sealers induces its antimicrobial properties [23].

Our study showed a significant difference in antimicrobial properties observed in MTA Fillapex, AH Plus and Endosequence $\mathrm{BC}$ at one hour. The antimicrobial activity of the tested sealers decreased over time. This shows that resin-based and bioceramic root canal sealers are more efficient in the freshly mixed state, and their antimicrobial properties decrease with time. However, the lowest long-term efficacy of $\mathrm{AH}$ Plus may be due to the paraformaldehyde released by this material only during the setting period. Similar studies were also reported by Hyeder et al. (2013), who discussed the antimicrobial properties of AH Plus owing to formaldehyde, which is released in small quantities during the setting reaction [23]. According to the manufacturers, the processing time of AH Plus is $4 \mathrm{hrs}$, and the setting time is $37^{\circ} \mathrm{C}$ for another $8 \mathrm{hr}$. Pizzo G et al. (2006) suggested that 24-h samples of AH Plus are ineffective in irradiating all E. faecalis in direct contact [28].

\section{Conclusion}

Within the limitations of the study, it was concluded that:

Endosequence $\mathrm{BC}$ had the maximum antimicrobial efficacy against all the tested microorganisms for both time intervals, followed by MTA Fillapex. The minimum efficacy was seen in AH Plus.

\section{References}

1. Spangberg L, Haapasalo M. Rationale and efficacy of root canal medicaments and root filling materials with emphasis on treatment outcome. Endod Topics 2002; 2:35-8.

2. Tuomas M. T. Waltimo, Markus Haapasalo, Matthias Zehnder, Jurg Meyer. Clinical aspects related to endodontic yeast infections. EndoTopics 2004; 9(1): 66-78.

3. Baumgartner JC, Siqueira JF, Jr, Sedgley CM, Kishen A. Microbiology of endodontic disease. Ingle's Endod 2008; 6(Canada): 285-87.

4. In vitro evaluation of the antimicrobial efficacy of four endodontic biomaterials against Enterococcus faecalis, Candida albicans and Staphylococcus aureus

5. Bogen G, Kuttler S. Mineral trioxide aggregate obturation: A review and case series. J Endod 2009; 5:777-90.

6. Torabinejad M, Watson TF, Pitt Ford TR. Sealing ability of a mineral trioxide aggregate when used as root end filling material. J Endod 1993; 19: 591-5.

7. Ali Allen Nasseh. The rise of bioceramics. Endod Prac 2009; 8:21-5. 
8. Candeiro GT, Correia FC, Duarte MA, Ribeiro Siqueira DC, Gavini G. Evaluation of radiopacity, pH, release of calcium ions, and flow of a bioceramic root canal sealer. J Endod 2012; 38:842-45.

9. Wang Z, Shen Y, Haapasalo M. Dentin extends the antibacterial effect of endodontic sealers against Enterococcus faecalis biofilms. J Endod 2014; 40:505-8.

10. Weiss El, Shalhav M, Fuss Z. Assessment of antibacterial activity of endodontic sealers by a direct contact test. Endo and Dent Trauma 1996; 12(4):179-184.

11. Sundqvist G, Figdor D, Persson S, Sjögren U. Microbiologic analysis of teeth with failed endodontic treatment and the outcome of conservative re-treatment. Oral Surg Oral Med Oral Pathol Oral Radiol Endod 1998;85:86-93.

12. Geetha RV, Veeraraghavan VP. Evaluation of antimicrobial activity of five root canal sealants against Enterococcus faecalis - An in vitro study. Int J Pharm Sci Rev Res 2016;40:221-3.

13. Gomes-Filho JE, Watanabe S, Bernabé PF, de Moraes Costa MT. A mineral trioxide aggregate sealer stimulated mineralization. J Endod. 2009; 35(2): 256-60.

14. Tanomaru-Filho M, Chaves Faleiros FB, Saçaki JN, Hungaro Duarte MA, Guerreiro-Tanomaru JM. Evaluation of $\mathrm{pH}$ and calcium ion release of root-end filling materials containing calcium hydroxide or mineral trioxide aggregate. J Endod. 2009; 35(10): 1418-21.

15. Singh G, Gupta I, Elshamy FM, Boreak N, Homeida HE. In vitro comparison of antimicrobial properties of bioceramic-based sealer, resin-based sealer and zinc oxide eugenol based sealer and two mineral trioxide aggregates. Eur J Dent. 2016;10:366-9.

16. Ustun Y, Sagsen B, Durmaz S, Percin D. In vitro antimicrobial efficiency of different root canal sealers against Enterecoccus faecalis. European J Gen Dent. 2013;2:134-8.

17. Shakya VK, Gupta P, Tikku AP, et al. An Invitro Evaluation of Antimicrobial Efficacy and Flow Characteristics for AH Plus, MTA Fillapex, CRCS and Gutta Flow 2 Root Canal Sealer. J Clin Diagn Res. 2016;10(8):ZC104-ZC108.

18. Singh G, Gupta I, Elshamy FM, Boreak N, Homeida HE. In vitro comparison of antimicrobial properties of bioceramic-based sealer, resin-based sealer and zinc oxide eugenol based sealer and two mineral trioxide aggregates. Eur J Dent. 2016;10:366-9.

19. Zhang P, McHugh CP Michalek S, Eleazer PD. pH required to kill Enterococcus faecalis in vitro. J Endod. 2004;30:218-9.

20. Lovato KF, Sedgley CM. Antimicrobial activity of endosequence root repair material and proroot MTA against clinical isolates of Enterococcus faecalis. J Endod. 2011;37:1542-6.

21. Poggio C, Al-Haddad A, Che Ab Aziz ZA. Bioceramic-based root canal sealers: A review. Int J Biomater 2017;2016:9753210

22. Hegde V, Rathod R. Assessment of antimicrobial efficacy of bioceramic sealer, epiphany self-etch sealer, and AH-Plus sealer against Enterococcus faecalis: An in vitro study. Endodontology. 2017;29:151-5. 
23. Heyder M, Kranz S, Völpel A, Pfister W, Watts DC, Jandt KD, et al. Antimicrobial effect of different root canal sealers on three microbial species. Dent Mater. 2013;29(5):542-49.

24. Stowe TJ, Sedgley CM, Stowe B, Fenno JC. The effects of chlorhexidine gluconate $(0.12 \%)$ on the antimicrobial properties of tooth colored ProRoot mineral trioxide aggregate. J Endod 2004; 30:429 31.

25. Al Hezaimi K, Al Shalan TA, Naghshbandi J, Oglesby S, Simon JH, Rotstein I. Antimicrobial effect of two mineral trioxide aggregate (MTA) preparations against Enterococcus faecalis and Streptococcus sanguis in vitro. J Endod 2006;32: 10536.

26. Aravind S, Gopikrishna V, Jeyavel RK, Kandaswamy D. Comparative evaluation of the antimicrobial efficacy of five endodontic root canal sealers against Enterococcus faecalis and Candida albicans. J Conserv Dent 2006;9:2-12

27. Mickel A.K., Nguyen T.H., Chogle S.Antimicrobial activity of endodontic sealers on Enterococcus faecalis. JOE (2003);29 (4): 257-258.

28. Pizzo G, Giammanco GM, Cumbo E, Nicolosi G, Gallina G. In vitro antibacterial activity of endodontic sealers. J Dent 2006; 34:35-4.

\section{Figures}

\section{Comparison of Mean Microbial Count for $\underline{\mathrm{AH}}$ Plus in different time intervals}

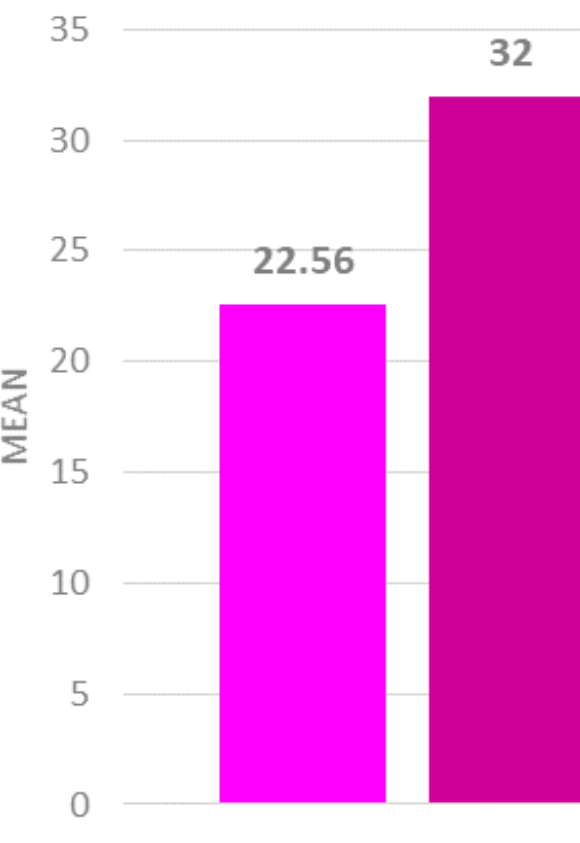

\section{E. faecalis}

30.1

\subsection{8}

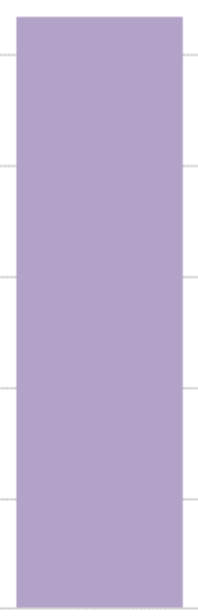

C.albicans
26.78

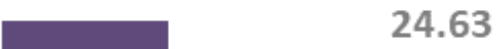

24.63

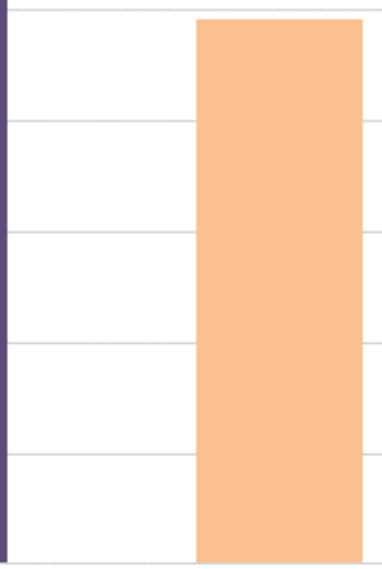

S.aureus 
comparison

Page 10/10 